\title{
Urgences
}

\section{Rocaille : octobre}

\section{Gilles Hénault}

Numéro 16, mars 1987

D.G. Jones : d'un texte, d'autres

URI : https://id.erudit.org/iderudit/025392ar

DOI : https://doi.org/10.7202/025392ar

Aller au sommaire du numéro

Éditeur(s)

Urgences

ISSN

0226-9554 (imprimé)

1927-3924 (numérique)

Découvrir la revue

Citer ce document

Hénault, G. (1987). Rocaille : octobre. Urgences, (16), 58-59.

https://doi.org/10.7202/025392ar d'utilisation que vous pouvez consulter en ligne.

https://apropos.erudit.org/fr/usagers/politique-dutilisation/ 


\section{Gilles Hénault ROCAILLE: OCTOBRE}

Il bruine sur des ruines

d'ombres, c'est la

tombe des fleurs

Cela prend les couleurs des feuilles tombées. Encore ce sont les pierres qui fleurissent

comme un florilège de tomes où toujours ceux qui s'en vont vont parler

De plus en plus ma bouche est remplie de pierres

et les ossements de mes pairs

semblent des fleurs

Est-ce, mêlés, le paradis

ou Angkor Vat

ou la cité interdite après

10 heures? Ce n'est pas

vivant ou mort

ni humain. En passant sous la pluie, scrmbrement, je vois un bouquet de runes 
Montréal, le 20 janvier 1987

Mon cher Bonenfant,

Par reconnaissance envers D.G. Jones et par amitié pour toi, j'ai tenu à faire une «nontraduction» ou «retraduction» du beau poème intitulé: «Rock Garden: October».

Chaque fois que je traduis un poème, je tente de conserver ou de reproduire le rythme de l'original: la cadence, le découpage, l'énergie propre à chaque vers. Je tiens compte aussi des assonances, des rimes internes, des jeux de mots. Ainsi, dans le premier vers, à cause de «rain» et «ruin», j'ai transformé la pluie en bruine. Au huitième vers, j' ai tenté d'imiter le jeu de mot «are gone go on» par une approximation pas très heureuse: «s'en vont vont». Au douxième vers, j'ai remplacé les collègues par des pairs. J'espère que les collègues ne m'en voudront pas. Dans l'original, le langage de Jones est très bref, très économique. J'ai tenté de reproduire cette économie. Cependant, je me rends bien compte que le poème original demeure intégral dans son authenticité, et que je n'en ai fait qu'une pâle transposition. 